INTERNATIONAL DESIGN CONFERENCE - DESIGN 2018

https://doi.org/10.21278/idc.2018.0417

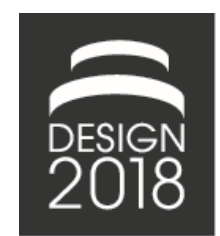

\title{
AN EXPLORATORY STUDY ON THE USE OF NEW DESIGN METHODS IN DESIGN CONSULTANCIES
}

\author{
A. Filippi, A. Suarez Madrigal, B. Eisenbart and K. Gericke
}

\begin{abstract}
This paper explores the uptake of design methods in design consultancies. Our results show that new methods are primarily used in the initial phases of the design process for specific problems. The main motive for doing so is to enhance creativity and understanding of the user. Many participants modify methods to fit specific needs or develop own methods. These findings highlight the need to improve the link between industry and academia in order to increase method awareness and use. Potential ways to improve this include better descriptions of methods and the be-nefits provided.
\end{abstract}

Keywords: design methods, design methods use, design research, design practice, design consultancies

\section{Introduction}

For many years researchers have studied the benefits of design methods and how they are applied in companies in order to be efficient in delivering better outcomes. This research suggests that there is substantial benefit in the use of design methods as an important resource to manage complexity in product development and creating innovation to maintain or advance competitiveness in the markets (Jagtap et al., 2014). There is wide agreement in the design research community that methods are necessary to support companies in improving their product development processes, and to be able to produce and deliver high quality products (Blessing and Chakrabarti, 2009). Teaching designers to apply design methods appropriately and effectively is hence a vital aspect of design education (Pahl et al., 2007).

Researchers are constantly proposing new design methods but their transfer from academia into industry is often said to be poor (Wallace, 2011). Jagtap et al. (2014, p. 4) argue that "while design methods have the potential to improve the product development process, their dissemination and use in companies is limited and lower than one might expect". Wallace (2011, p. 247) refers to this poor transfer as the "missing link" between industry and research. There are several barriers that make the adoption of design methods in practice a difficult task and impair their easy implementation (Jagtap et al., 2014; Eisenbart et al., 2017). In spite of the discussed missing link, there are many examples of successful adoption of design methods in practice (Gericke et al., 2016). This begs the question, how, by which specific motivations, and under which circumstances industry will seek to implement new design methods and what might foster this process. This paper aims to obtain insights into this issue through an empirical study.

One of the main challenges for developing design methods is gaining an understanding of what enables the successful application of a method in a specific context (Gericke et al., 2016). In this sense, the aim of this research is to understand when and why design consultancies use new methods and in which ways they adapt and apply them. The study focuses on design consultancies as they tend to work with several clients with different kinds of problems. This requires them to be versatile in finding and applying design 
methods that fit the companies' challenges and context. In particular we will focus on the motivations, situations and conditions in which design consultancies are willing to adopt new methods. The study is guided by three main research questions: (1) When do design consultancies adopt new methods? (2) Why do design consultancies adopt new methods? (3) How do they adapt these new methods?

The first question is aimed at understanding in which particular situations the design consultancies find a need to search for new methods. The second question tries to gain information about the motivations and the reasons behind their choice to use a new method. The third question is targeted at discovering the specific ways in which firms adapt the methods that they decide to use. The presented results are based on a survey that was answered by 32 design practitioners from different design consultancies. As this topic is under-researched, the study is designed as an explorative investigation and does not constitute a representation for all uses of design methods. Nonetheless, it provides a contribution in shedding light on situations leading to the (successful) uptake of design methods in a variety of different contexts.

\section{Transfer and application of design methods}

There are many definitions of design methods. Varying interpretations by scholars of what this term means (Gericke et al., 2017) is in step with the diverse and ambigous use by practitioners (Gericke et al., 2016). Hereafter, a method is understood as "a systematic procedure intended to reach a specific goal" (Pahl et al., 2007). "This may include specifications of how information is to be shown, what information is to be used as inputs to the method, what tools are to be used, what actions are to be performed, how the task should be decomposed and how actions should be sequenced" (Gericke et al., 2017, p.105).

\subsection{Current state of the use of design methods}

Many factors are discussed as contributing to the problem of limited knowledge transfer between industry and academia. A scarce application of methods in practice has been associated to poor support from research on how methods should be applied in practice (Ponn and Lindemann, 2006; Gericke et al., 2011; Roschuni et al., 2011). Methods, are generally seen by practitioners as: "too complex, inflexible and fail to match their working practices" (Wallace, 2011, p. 247). On the other hand, there is no clear understanding from design research of what the designers need in order to apply and use methods successfully and effectively (Lindhal, 2006; Jagtap, 2014). Also, companies are often not aware of the existence of new methods or the benefits that these methods could bring to their processes and outcomes (Araujo et al., 1996).

López-Mesa and Bylund (2011) found out that many methods employed within Volvo car Corporation are different from those developed by academia. In some cases modifications are applied in order to improve the methods, but there is a lack of objectivity in methods modification. As a consequence the methods are at times improved, while, in other cases, the adjustments lead to unreliable results.

The uptake of methods has been studied in order to find solutions to these problems. Some requirements for improving methods transfer between academia and industry have been identified. For instance, a need for simple and pragmatic methods in companies has been observed (Birkhofer and Kloberdanz, 2005); next to that scholars, highlight the need to directly visible benefits and concrete results (Tomiyama et al., 2009). Wallace (2011, p. 247) referring to Birkhofer et al. (2002), states that "design methods will only be adopted when set on four pillars: simplicity, adaption, promotion and training". A framework with the aim to gather all the factors that can influence the uptake of methods in product development companies has been defined by Jagtap et al. (2014). This would help to better develop design methods and to disseminate them in companies. By contrast, Ponn and Lindemann (2006) mention mainly two aspects to take into consideration: the designer's individual characteristics and a systematic support aiming at the specific design situation.

\subsection{Web-based method databases}

Increased availability of method databases on the internet also presents a potential solution to the problem of knowledge transfer, as it gives access to an extensive and broad range of design methods. Practitioners evaluate the quality of such portals by considering two aspects: the quality of the offered contents and the possibilities to quickly access relevant contents (Ponn and Lindemann, 2006). One of 
the challenges is that these repositories are generally arranged based on the names of the methods or according to a generic design process and not in the way that designers generally look for those, based on outcomes (Gericke et al., 2016).

\subsection{Consultancies}

Within the landscape of user-centered design, the terms co-design and co-creation are becoming more and more relevant (Sanders and Stappers, 2008). This new way of doing design seems to be especially relevant in consultancies since "co-designing requires creative initiative on the part of the entire team: researchers, designers, clients and the people who will ultimately benefit from the co-designing experience" (Sanders and Stappers, 2008). In general, scientific research on the use of design methods in consultancies is limited, since most of the literature analyses the use of methods either from the viewpoint of more traditional design companies or from an academic perspective that is disconnected from industry specific contexts. The following chapter presents the empirical study conducted to better understand the phenomenon.

\section{Study design}

The research presented here investigates the specific situations and motivations for design consultancies to use new design methods in their practice, by looking into when they use the methods, the type of adaptations they apply to them, and the reasons behind those decisions. To answer the proposed research questions, an explorative, empirical study was conducted with respondents from different design consultancies that use design methods regularly.

\subsection{Data collection method}

A web-based survey using Qualtrics, written in English, including both closed and open-ended questions was used to collect the data during the study. (https://www.dropbox.com/sh/3j7eza9uylxa8nx/AAA3Yhk_DjzODzsVmG_eCeqka?dl=0).

The use of a survey allows gathering both quantitative and qualitative data. According to Wisdom and Creswell (2013, p. 1), the integration of the two methods "permits a more complete and synergistic utilization of data than do separate quantitative and qualitative data collection and analysis".

Given that "the notion of method causes a surprising amount of confusion among engineering designers in industry and academia" (Gericke et al., 2016), the survey included an introduction where a short definition of a design method is given. It was considered important that the study participants had a similar understanding of the term method, not to be confused with methodologies, design processes or tools.

After the introduction, two contextualising questions were presented to help participants have the same understanding of the topic. In those questions, it was asked which methods they use the most and which methods they know or have used in the past, by providing a list of popular methods to select from. The methods provided were mostly selected from the design method cards by IDEO (2003). The participants were encouraged to add additional methods used by their design team or their company to leave room for their input.

The main part of the survey consisted of 14 questions, most of them open-ended. The survey was structured in a way that respondents were first invited to think about a situation from past experiences and then they were gradually steered to express opinions and give information about the present. In the last part they are motivated to reflect on their experiences and think about possible future actions ("Would you use the method again?"). This helped to understand if the use of a new method was regarded as a good decision or not, even though it is understood that "future-oriented questions involve considerable speculation, and responses to questions about future actions or attitudes are typically less reliable" (Patton, 2002). Lastly, demographic data was collected to help understand the sample better.

A first draft of the survey was piloted with six peers with a similar profile as the target sample in order to identify inconsistencies and improve intelligibility of the questions. The survey was also iterated with feedback and criticism from discussions between the researchers and peers performing similar studies. Overall, the study was performed in four general phases: survey preparation and testing, participant recruitment, data collection and data analysis. 


\subsection{Participant recruitment and sample profile}

Participants were recruited via email, personal mobile messages, and direct messaging through the professional social network LinkedIn. The survey was also published and shared in different social media platforms and re-shared by other people. Over 110 potential respondents were contacted directly by the researchers. The total number of responses contemplated as valid and overall complete was 32 , while seven were only partly analysed due to incompleteness in answering important questions. The completed surveys represent a $29 \%$ response rate from the 110 people contacted directly.

Only 23 out of the 32 participants shared their highest level of studies. From the 23, the majority posses a Master degree $(\mathrm{n}=15)$, six have a Bachelor degree, and two a PhD. Likewise, 23 shared their discipline of study. 21 studied design, one Business, and one Marketing.

The survey was responded by one intern, two junior designers, six designers, four senior designers. Seven participants had managerial or leadership positions, three a director position and three were either company founders or partners in CEO or similar positions. The years of Design experience ranges from 1 to 30 years with an average of 9.7 years.

Consultancy sizes varied considerably from one person (self-employed consultant) to an international, globally acting consultancy with 12,000 employees, from which ca. 11,000 are designers, as reported by the respondent. Number of people in design roles vary from one to 11000 people. Design teams sizes range from one to 40 people.

Although the companies represented by respondents work for many different industries, some of the most common ones are: Medical/health care $(n=15)$, FMCG (fast-moving consumer goods) $(n=13)$, financial institutions $(\mathrm{n}=10)$, automotive $(\mathrm{n}=10)$, construction $(\mathrm{n}=9)$ and services $(\mathrm{n}=8)$. All respondents work as consultants for these industries as part of design consultancies and not inside the companies in those markets themselves.

Ages of respondents range from 23 to 62 years. The average age of respondents is 33.5 years, with a median of 30.5 years. 17 respondents were male $(56.67 \%)$ and 13 female $(43.33 \%)$. Respondents from different countries participated in the survey. These include: China, Germany, India, Italy, Luxembourg, Mexico, Netherlands, Sweden, Switzerland and United Kingdom.

\subsection{The survey}

Data was collected between May and June, 2017. The survey was available in English for all respondents, whose native languages include: Chinese, Dutch, English, French, German, Hindi, Italian, Spanish and Swedish. Overall, 49 people accessed the online survey but only 32 of those were valid responses. The most common reason for this was unanswered surveys. To consider a survey valid we screened it through our sample criteria for participants. They had to: i) work for a design consultancy or agency; ii) be design practitioners; iii) use design methods. The average time for completion of the questionnaire was 19 min.

The survey consisted of 15 questions in total where participants were encouraged to refer to both ongoing and recent design projects that they had been involved in where they used new design methods. Central questions included:

- "In which steps of the design process did you use the method?";

- "Please describe in detail the last time your team decided to use a new design method";

- "What did you use the design method for";

- "What triggered the use of a new method";

- "What was the outcome you were expecting when selecting the new method?";

- "Did you use the method exactly as described or did you modify something?";

- "If you modified it, how did you modify it?";

The questionnaire alternates qualitative and quantitative questions since, as described before, this allows a more complete data collection (Wisdom and Creswell, 2013).

For the analysis of the qualitative data collected inductive coding of data was performed (Blessing and Chakrabarti, 2009). First a cycle of initial coding was performed individually by each of the researchers. Afterwards, the two sets of codes were compared and discussed, and modified accordingly to obtain a unified code set. Afterwards, we followed a process of grouping themes from the most common terms 
that were induced from the data. Answers from each participant were labelled according to said themes. The given answers were also analysed individually and across different surveys, in order to determine any type of concepts, themes, and opinions addressed by the participants for our analysis. From the quantitative data, the percentages of the different responses have been used for the correlational analysis by looking at the information both by individual and across participants responses.

\section{Findings}

Using the introductory questions discussed in the method section helped developing an understanding of the topic and allowed the participants to get acquainted with the survey. In the following section results related to the three main research questions are presented complemented with context information that was also deemed relevant for this research.

\subsection{When do design consultancies use new design methods?}

This research question is aimed at understanding in which phases of the design process, design consultancies are open to use new methods more commonly. Figure 1 shows the results for the question: When do design consultancies use new design methods? The bars indicate phases of the design process in which participants used a new design method in a particular situation previously described by them. Respondents were allowed to choose all phases that applied to their specific situation. The most prominent results were that $70 \%(\mathrm{n}=23)$ out of 33 respondents used a new method during the idea generation phase, $55 \%(\mathrm{n}=18)$ of the participants used it during concept development and context analysis. and $52 \%(\mathrm{n}=17)$ in the problem definition phase. The phase in which a new method was less frequently used is implementation with only $21 \%(n=7)$ of the cases.

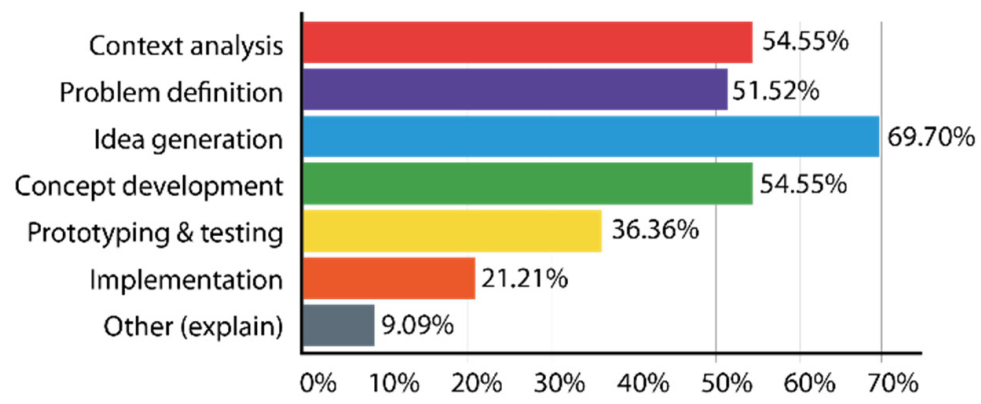

Figure 1. Use of design methods in different phases of the design process

\subsection{Why do design consultancies use new design methods?}

The second research question intends to explore the reasons behind the motivations to use a new method. Hereafter, responses to two questions related to this topic are presented.

\subsubsection{Reasons for selecting a new design method}

The question was answered by 31 participants. Ten out of these 31 participants (32\%) considered generation of new ideas and stimulation of creativity as the main reasons that pushed them to use a new method. Equally, ten respondents referred to a better understanding of the user and their needs while describing the motivations for applying the new method. Besides these results we also found out that three practitioners talked about envisioning the future while three of them used a new method to foster discussion among stakeholders. Less frequent answers included aspects such as validation of ideas with customers $(n=2)$ better communication $(n=3)$, collaboration within the team and with external stakeholders $(\mathrm{n}=2)$; while three of them provided general answers that are not addressable to any specific cluster. It is important to mention that seven participants out of 31 selected more than one reason.

Figure 2 presents the specific reasons to select a new method. The most common response was: "a specific type of problem" (i.e. a type of problem for which currently used methods are not effective) with $52 \%$ of responses $(n=16)$. Next to that is: "a specific outcome" with $35 \%(n=11)$, then "stuck in the design process" with $19 \%(\mathrm{n}=6)$ and "currently used methods were not effective", with $16 \%(\mathrm{n}=5)$. 
About the latter, one specific situation reflected the need to create a new method ("customer journey wheel") because the one existing did not satisfy the actual need, in fact they wanted to have "an overview where [it] was possible to see linkages". The least selected answer with only two responses had to deal with a client requesting the use of the new method while one respondent, by choosing the choice "other", mentioned the fact of using a method the client was familiar with. It is important to mention that eight respondents chose "other" as the response, but since they mention a wide variety of reasons they cannot be aggregated in any other category. Reasons under this category include creating fun and excitement during the ideation phase, being keen of trying new approaches, or seeking richer results.

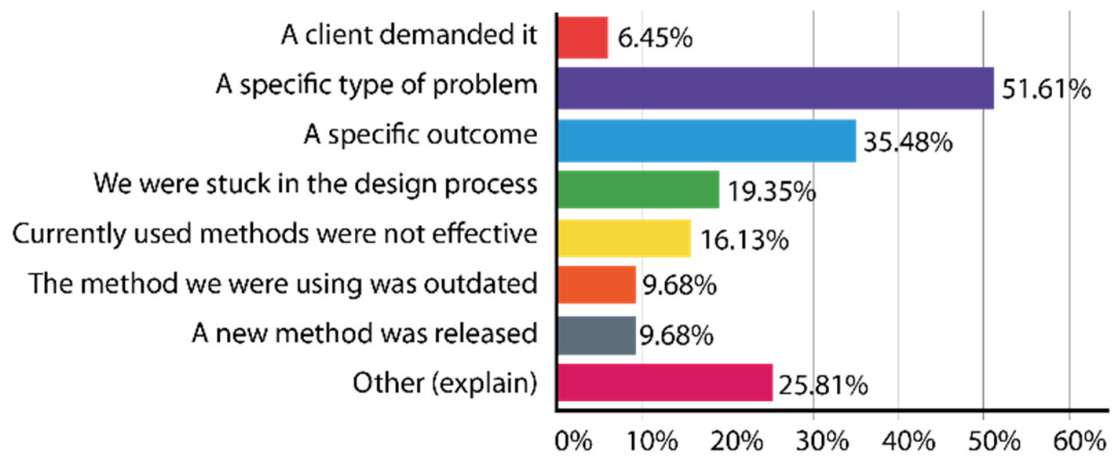

Figure 2. What triggered the use of a new method?

\subsubsection{Outcome expected from the use of a new method}

This question was aimed at understanding what were the expected effects that designers had in mind when deciding to use a new design method. 28 answers for this question were analysed qualitatively, coded and grouped using inductive coding. The most common category comprising $33 \%$ of responses $(n=9)$ was related to user understanding. The data in this group makes references to outcomes like knowing more about the user's context, have more empathy with them, or improve their experience. Secondly, methods were expected to be an enabler for creativity. Some of the responses refer to providing with more creative ideas, improve creativity sessions, help in making an innovation session more fluent, stimulate noncreative teams. From the sample, $25 \%(\mathrm{n}=7)$ of the reactions were connected to this category. Third, $18 \%$ of replies $(n=5)$ were related to communication, for example to spark a rich conversation or get a discussion started, or to improve communication within different disciplines or making communication easier. Similarly, $18 \%$ of responses $(n=5)$ were related to some type of improvement such as better products, processes, user interfaces or work environment. Figure 3 shows these results.

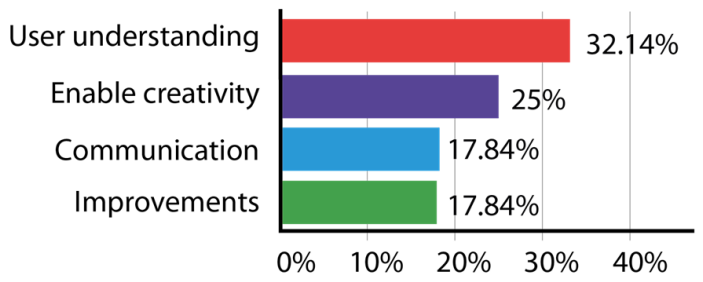

Figure 3. What did you expect from using the new method?

\subsection{How do they adapt the new methods?}

In order to concisely understand if designers modified their methods, it was asked if they used them as described or if they modified something. $67 \%$ of participants indicated to have modified something in the method they used, while 33\% marked "used exactly as described".

\subsubsection{Modifications of new design methods}

The objective of this question was getting a more specific understanding of how people modified the methods that they used. The result (see Figure 4) was that 14 out of 21 answers $(67 \%)$ referred to having 
mixed methods. Also, $43 \%$ of replies $(n=9)$ selected the option of deleting steps that were considered unnecessary for their particular context. The least selected option was adding missing steps with roughly $33 \%$ of participants choosing it $(\mathrm{n}=7)$. Responses for the "other" option will be analysed and reported in the next section of this paper.

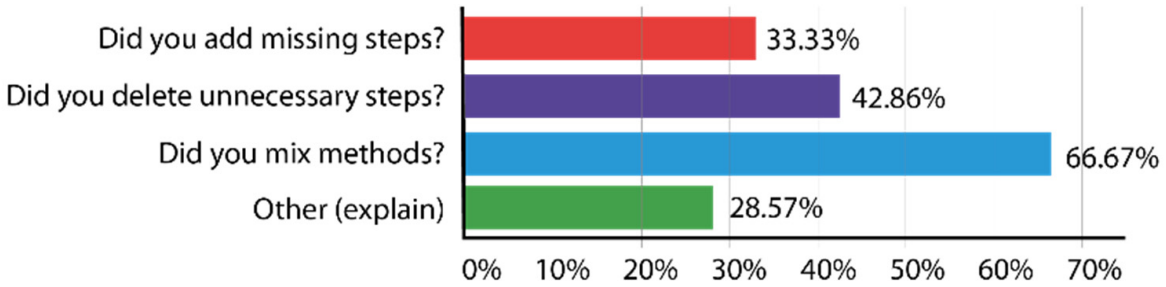

Figure 4. If you modified the method, did you add missing steps/delete unnecessary steps/mix methods/other?

\subsubsection{Level of satisfaction of the use of new design methods}

Figure 5 shows the percentage of participants that would consider the prospect of using the new method again and the ones that wouldn't. This might give an idea of the level of satisfaction or perception of utility that the users got from their use experience. Out of 31 respondents, $27(87 \%)$ indicated they would use the new method again. Only two people would not use the new method again $(6 \%)$, and the remaining two $(6 \%)$ mentioned that they didn't know if they would use it again as they were waiting for the results after using the method or were in the process of using it at the time of the response.

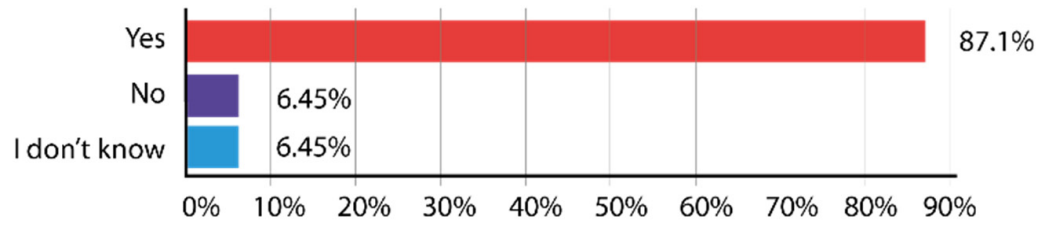

Figure 5. Would you use the new method again?

Figure 6 shows how many people are still using the new method. The result shows that $77 \%$ of respondents are indeed still using the method they described $(n=24)$, and only $6 \%$ are not $(n=2)$.

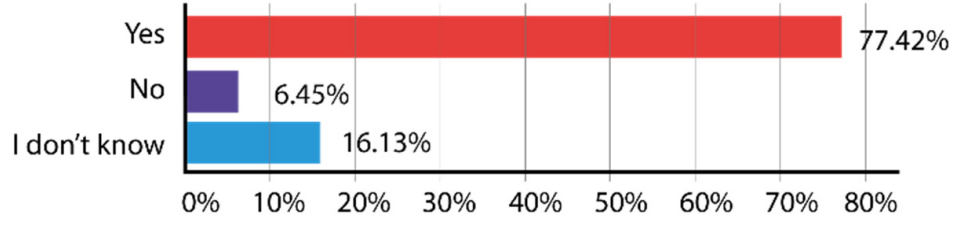

Figure 6. Are you still using the new method?

\subsubsection{Most common sources for design methods}

Through 31 open answers to the question: "Where did your team find the method?", we encountered that the most common source for new methods was literature and academia $(\mathrm{n}=10)$ representing $32.26 \%$ of responses. Next to that, $22 \%$ of the people refer to peers or colleagues $(n=7)$ and the same number of respondents $(\mathrm{n}=7)$ stated they have developed the methods themselves. Internet sources were the next choice with $16.13 \%(n=5)$. Least common responses included events like symposiums or conferences, or a trending method.

\section{Discussion}

As discussed in the introductory sections, many studies mention a lack of awareness about design methods in practice, specifically the area of design consultancies has been mostly unexplored (see 
Section 2). The study findings presented here provide an insight into the use of design methods in design consultancies and are aspired to be a starting point for further exploration.

\subsection{When and why design consultancies use new design methods?}

"Some design methods are targeted at frame breaking - creative problem solving, imagination, etc. whilst others are about understanding users and bringing their perspective into the articulation anthropology, empathic design, construct elicitation, etc.” (Bessant and Maher, 2009, p. 7)

\subsubsection{Creativity}

A large number of respondents noted to have used new design methods during idea generation and concept development phases. This suggests that practitioners in design consultancies apply methods whenever they cannot solve those problems (themselves) with the means they have normally at their disposal. Moreover, these early stages of the design process (idea generation and concept development) can be considered part of the "fuzzy front end' (FFE) where "there is no clear path on how to proceed" (Sanders and Stappers, 2012). As proposed by Kleef et al. (2005), design methods offer the potential to think outside the box. Analogously, ten out of 31 participants stated to have used a new design method in order to stimulate creativity and generate new ideas and seven of them considered creativity as the actual outcome expected from the new method used. In particular, the data suggests that, by using the method, they were expecting to have "better, more creative ideas", "stimulate a non creative team", "more agile and effective generative session", "create a creative ambience and setting".

The FFE has been defined by Mootee $(2011$, p. 1) as "an insight-driven, prototype-powered and foresight-inspired search for new ideas". It is not surprising, therefore, that Brainstorming -considered by Taylor et al. (1958) as "a means of facilitating creative thinking" and by Wallace (2013, p. 242) as "a method to help generate ideas", and Rapid Prototyping are two of the methods most commonly used and known by practitioners of our sample.

\subsubsection{User research}

Besides idea generation and concept development, other common phases where participants used new design methods are in context analysis and problem definition. Those phases are also part of the FFE that, as reported by Khurana and Rosenthal (1998), need to be shaped based on two kinds of external factors: market leadership and type of customer. Mootee (2011) also affirms that identifying customer needs and collecting insights is an aspect of the FFE. Stappers (2006) argues that one of the consideration to be made in this phase consists in the understanding of users and context of use. Accordingly, in our research, a consistent number of respondents (ten out of 31) stated they used the new method in order to have a better understanding of customer needs, contexts and points of view. Some examples are: "identify customer's point of view", "get customer insights", "understand product/user interaction". These findings can be supported by the fact that the majority of the respondents confirmed having used customer research methods in the past such as questionnaires and surveys (92\%), customer journeys (92\%), user interviews (90\%), personas (89\%) and user observations $(87 \%)$. As mentioned in Section 2, the use of participatory design has been growing in the last few years (Sanders and Stappers, 2012), and this can be seen in our study since, among those who used a new method for customer research purposes, the majority referred to participatory design or co-creation either directly or indirectly.

\subsubsection{Discussion, communication, collaboration}

With regard to the previous paragraph, Kleef et al. (2005), by referring to the study of Kohli and Jaworski (1990), suggest that gathering consumer understanding through customer research methods improve communication across departments. This is connected to the fact that one of the purposes for using design methods, therefore, consists in facilitating and supporting team work by improving communication and planning among team-members (Cross, 2000; Jagtap, 2014). Especially in design consultancies, there is the need to deal with a lot of stakeholders that come from different backgrounds and industries and with clients that are frequently changing whenever a new project starts. From the 
findings of our survey, we see that some respondents refer to these kind of situations by mentioning their intention to foster discussion, the importance of communicating the concept effectively and the need to collaborate with people from different backgrounds and levels of expertise. These findings are coherent with the previous remark about the use of new design methods in the FFE. According to Moenaert et al. (1995), one of the ways to reduce uncertainty, characteristic of the early stages of the design process, is by encouraging communication between $R \& D$ and marketing and having a decentralised project structure. The importance to collaborate and communicate with stakeholders seems to be increasing, especially in design consultancies. This also is in line with what has been suggested by Birkhofer and Kloberdanz (2005) who propose that the optimal use of design methods in industry is not only about the transfer between academia and industry but depends on the prerequisites of several stakeholders

\subsubsection{The importance of clients and outcome expected}

Surprisingly, despite the fact that some of our respondents mentioned the presence and the importance of clients in their design process and in their decisions, they don't consider them as a direct trigger to use a new method. Only two out of 31 stated having used a new method because a client demanded it. Rather, most of the participants mentioned that they mostly used a new method when a specific problem occurred and when a specific outcome was required. Some examples of the latter included "improve user centered approach", "need to differentiate from competition", "integration with other company", "spark creativity", "enhance the quality of our work". In the same way Cross (2007) proposes two main purposes for using design methods: they are important in the assessment of design problems, and also in the development of design solutions. Likewise, Gericke et al. (2016) encountered that: "many of the interviewed practitioners search for methods primarily based on outcomes". Additionally, the fact that companies are often not aware of the benefits that new methods could bring to their processes and outcomes (Araujo et al., 1996), can be an indication of the fact that the use of methods in companies is limited (Araujo et al., 1996; Birkhofer et al., 2002; Wallace, 2011; Gericke et al., 2016; Eisenbart and Kleinsmann, 2017).

\subsubsection{Envisioning}

In parallel with customer research, participants refer to the use of methods in order to envision future scenarios, contexts and needs. Sanders $(2002$, p. 1) mentions that "designers have been moving increasingly closer to the future users of what they design". In particular, when co-designing, stakeholders collaborate with designers with the aim to create knowledge about "future and desirable situations and products" (Steen et al., 2007).

As mentioned before, some of the practitioners of our survey stated the necessity to deal with people from different backgrounds and the importance to stimulate discussion and communication between parties. That explains why most of the people that alluded to envisioning methods also refer to the importance to spark discussion about future scenarios.

\subsection{How do design consultancies adapt the new methods?}

As presented in the findings section, $67 \%$ of respondents (20 out of 30 ) indicated they modified something in the methods they used in order to adapt them to their needs. Furthermore, many of these responses are from people who said they created the methods themselves, which effectively implies a singificant modification from other existing methods. On the one hand, these findings can be related to the fact that methods are scarcely used because of the seemingly limited support from research on how methods should be applied in practice (Ponn and Lindemann, 2006; Gericke and Blessing, 2011; Roschuni et al., 2011). On the other hand, Wallace (2011) suggests that all methods should be adapted to the context and applied flexibly. Their purpose it is to support the design process and they should not simply be undertaken as routine tasks". Accordingly, it can be proposed that, within design consultancies, the 'best practice' of using methods flexibly and adapting them to the specific context is becoming a common practice.

In our research, some of the most common sources for methods consisted in peers or other team members' knowledge (seven out of 31), while others developed them themselves (seven out of 31). This 
might also be related to the fact that, it is often the case that methods "are just part of the "shared understanding' [...] members of the team bring with them their experience of the development path which they acquired from working on previous company projects" (Wallace, 2011, p. 241). Nonetheless, the most common source for new methods in design consultancies in our sample is literature (eight out of ten) while only two respondents chose academia. This result is quite relevant because it suggests that designers prefer to look up for methods independently.

\subsection{Was the use of the new method a good choice?}

The majority of our respondents claimed that they would use the new method again (87\%) and among those, $77 \%$ are still using it. That slight difference comes from the fact that three people didn't have information regarding the continued use of the method by their company. This is an indication of the perception of a positive impact from the method on the design process. As mentioned by Jagtap et al. (2014) there are various studies that indicate the positive effects of design methods (e.g. Eisenbart and Kleinsmann, 2017). However, this could also mean that companies are often not aware of the existence of new methods and their benefits (Araujo et al., 1996) and, as a consequence, they have the tendency to stay attached to methods they feel confident with.

\subsection{Limitations}

The presented study has several limitations. Those essentially concern its limited generalisability because of the small sample size, the limited comparability of responses due to the diverse sample profile, which includes consultancies that work in very diverse industries. Yet, the study provides an insight into the uptake of design methods in the context of diverse design consultancies and shows several consistencies across these. It stands to reason that the discussed findings will similarly apply to consultancies beyond the shown data set. By trying to understand the circumstances and the motivations when design consultancies look out for new methods, the study aims to provide a starting point for future research.

\section{Conclusions}

This paper intended to explore the uptake of design methods in the specific industry of design consultancies. The literature suggests that knowledge transfer of design methods between academia and industry is poor. By focusing on design consultancies, the study offers a perspective on the use of design methods in practice that has thus far been rarely researched. In particular, the paper aims at exploring the circumstances and the motivations when these companies search new methods to apply in their design processes.

Overall, the obtained findings show consistency with previous studies on the use of design methods, showing that the participating design consultants mostly use new methods in the initial stage of the design process which is the most uncertain phase, as the use of design methods helps them cope with its inherent unpredictability. The study suggests that new design methods are mainly used in practice to help structure the process and find a way to proceed especially in the FFE. Those findings are supported by the fact that the respondents look for new methods when they need to solve specific problems.

One of the main reasons why practitioners use new design method concern the call for creativity. Besides that, due to the recent shift from the traditional design process to co-design, an increasing use of design methods aimed at improving communication and collaboration has been observed with a concurrent focus on users. It is interesting to note that clients are not an influencing aspect in the choice of new design methods, this can show the fact that the design process remains a prerogative of consultancies. Concerning the concept of adaptation of methods the results show a clear inclination to modify them according to the specific needs required in every project. A good number of respondents also stated to have developed their own methods. This can be seen as evidence that methods are useful in their practice but it also suggests that the existing methods are not yet satisfying their specific needs as they are, and that's why they are generally modified.

These findings suggest that the link between academia and industry should be improved further. On one hand, academia should satisfy the demand of the industry to be provided with helpful and adaptable 
design methods. On the other hand, awareness on their specific benefits and contribution to solve problems should be clearly stated in order to increase the reputation about design methods in practice. As the design process is evolving, the academic community should pay special attention at the development and enhancement of design methods for collaboration and involvement of stakeholders. However, our findings take into consideration a limited area of context and are based on a limited sample. Since the area of design consultancies is still mostly unexplored in research, it would be interesting in future research to conduct a larger qualitative study to get a better understanding of the recent change towards a more collaborative design approach.

\section{References}

Araujo, C.S., Benedetto-Neto, H., Campello, A.C., Segre, F.M. and Wright, I.C. (1996), "The utilization of product development methods: a survey of UK industry", Journal of Engeering Design, Vol. 7 No. 3, pp. 265-277. https://doi.org/10.1080/09544829608907940

Bessant, J. and Maher, L. (2009), "Developing radical service innovations in healthcare-the role of design methods", International Journal of Innovation Management, Vol. 13 No. 4, pp. 555-568. https://doi.org/10.1142/S1363919609002418

Birkhofer, H. and Kloberdanz, H. (2005), "An Extensive and Detailed View of the Application of Design Methods and Methodology in Industry”, Proceedings of the ICED'05 / $15^{\text {th }}$ International Conference on Engineering Design, Melbourne, Australia, August 15-18, 2005, The Design Society, Glasgow.

Birkhofer, H., Kloberdanz, H., Sauer, T. and Berber, B. (2002), "Why design methods don't work and how to get them to work", Proceedings of the EDIProD 2002 / 3rd International Seminar on Engineering Design in Integrated Product Development, Zielona Gora, Poland.

Blessing, L. and Chakrabarti, A. (2009), DRM: A Design Research Methodology, Springer, London. https://doi.org/10.1007/978-1-84882-587-1

Eisenbart, B. and Kleinsmann, M. (2017), “Implementing Shared Funcion Modelling in Practice: Insights from Six Companies Designing Mechatronic Products and PSS”, Journal of Engineering Design, Vol. 28 No. 1012, pp. 765-798. https://doi.org/10.1080/09544828.2017.1395395

Eisenbart, B., Gericke, K. and Blessing, L.T.M. (2017), "Taking a Look at the Utilisation of Function Models in Interdisciplinary Design: Insights from Ten Engineering Companies", Research in Engineering Design, Vol. 28 No. 3, pp. 299-331. https://doi.org/10.1007/s00163-016-0242-3

Gericke, K. and Blessing, L. (2011), "Comparisons of design methodologies and process models across domains: a literature review", Proceedings of the ICED'11/18 th International Conference on Engineering Design, Vol. 1: Design Processes, Lyngby, Copenhagen, Denmark, August 15-19, 2011, The Design Society.

Gericke, K., Eckert, C. and Stacey, M. (2017), “What do we need to say about a design method?", Proceedings of the ICED'17 / $21^{\text {st }}$ International Conference on Engineering Design, Vol. 7, Vancouver, Canada, August 2125, 2017, The Design Society, Glasgow, pp. 101-110.

Gericke, K., Kramer, J. and Roschuni, C. (2016), “An Exploratory Study of the Discovery and Selection of Design Methods in Practice", Journal of Mechanical Design, Vol. 138 No. 10, pp. 101109. https://doi.org/10.1115/1.4034088

Jagtap, S., Warell, A., Hiort, V., Motte, D. and Larsson, A. (2014), "Design methods and factors influencing their uptake in product development companies: A review", Proceedings of the DESIGN $2014 / 13^{\text {th }}$ International Design Conference, Dubrovnik, Croatia, May 19-22, 2014, The Design Society, Glasgow, pp. 231-240.

López-Mesa, B. and Bylund, N. (2011), "A study of the use of concept selection methods from inside a company", Research in Engineering Design, Vol. 22 No. 1, pp. 7-27. https://doi.org/10.1007/s00163-010-0093-2

Moenaert, R.K., De Meyer, A., Souder, W.E. and Deschoolmeester, D. (1995), "R\&D/marketing communication during the fuzzy front-end”, IEEE Transactions on Engineering Management, Vol. 42 No. 3, pp. 243-258. https://doi.org/10.1109/17.403743

Mootee, I. (2011), "Strategic innovation and the fuzzy front end", Ivy Business Journal, No. March/April 2011.

Pahl, G., Beitz, W., Feldhusen, J. and Grote, K.-H. (2007), Konstruktionslehre: Grundlagen erfolgreicher Produktentwicklung, Methoden und Anwendung, Springer, Berlin, Heidelberg. https://doi.org/10.1007/978-3540-34061-4

Ponn, J. and Lindemann U. (2006), "CIDAD - A method portal for product development", Proceedings of the DESIGN $2006 / 9^{\text {th }}$ International Design Conference, Dubrovnik, Croatia, May 15-18, 2006, The Design Society, Glasgow, pp. 1221-1228.

Roschuni, C., Agogino, A. and Beckman, S.L. (2011), "Supporting the Design Community of Practice", Proceedings of the ICED'11/ $18^{\text {th }}$ International Conference on Engineering Design, Vol. 8, Copenhagen, Denmark, August 15-19, 2011, The Design Society, Glasgow, pp. 255-264. 
Sanders, E. and Stappers, P.J. (2012), Convivial toolbox: Generative Research for the Front End of Design, BIS Publishers, Amsterdam.

Sanders, E.B.N. (2002), "From user-centered to participatory design approaches", In: Frascara, J. (Ed.), Design and the social sciences: Making connections, CRC Press, London, pp. 1-8.

Sanders, E.B.N. and Stappers, P.J. (2008), "Co-creation and the new landscapes of design", CoDesign, Vol. 4 No. 1, pp. 5-18. https://doi.org/10.1080/15710880701875068

Steen, M., Kuijt-Evers, L. and Klok, J. (2007), "Early user involvement in research and design pro-jects. A review of methods and practices", Proceedings of the 23rd EGOS Colloquium, Vienna, Austria, July 5-7, 2007, European Group for Organizational Studies, pp. 5-7.

Taylor, D.W., Berry, P.C. and Block, C.H. (1958), "Does group participation when using brainstorming facilitate or inhibit creative thinking?", Administrative Science Quarterly, Vol. 3 No. 1, pp. 23-47. https://doi.org/10.2307/2390603

Tomiyama, T., Gu, P., Lutters, E. and Kind, C. (2009), "Design Methodologies: Industrial and Educational Applications", CIRP Annals, Vol. 58 No. 2, pp. 543-565. https://doi.org/10.1016/j.cirp.2009.09.003

Wallace, K. (2011), "Transferring design methods into practice", In: Birkofer, H. (Ed.), The future of design methodology, Springer, London, pp. 239-248. https://doi.org/10.1007/978-0-85729-615-3_21

Wisdom, J. and Creswell, J.W. (2013), Mixed Methods: Integrating Quantitative and Qualitative Data Collection and Analysis While Studying Patient-Centered Medical Home Models, AHRQ Publication No. 13-0028-EF, Agency for Healthcare Research and Quality, Rockville.

Anna Filippi, Bachelor Degree

Delft University of Technology, Strategic Product Design

Poppesteeg 1D, 2611BG Delft, Netherlands

Email: a.filippi@student.tudelft.nl 